\title{
A DISEASE WITH IMMUNE DEFICIENCY, SKIN ABSCESSES, PANCYTOPENIA, ABNORMAL BONE MARROW KARYOTYPE, AND INCREASED SISTER CHROMATID EXCHANGES: AN AUTOSOMAL RECESSIVE CHROMOSOME INSTABILITY SYNDROME?
}

\author{
Yasuhide Yanabe, ${ }^{1}$ Hiroyuki NunOI, ${ }^{1}$ Hiroyuki TsuchiYa, ${ }^{1}$ \\ Shigenori HrguchI, ${ }^{1}$ Izumi AKaboshI, ${ }^{1}$ Akihiko Kitano, ${ }^{1}$ \\ Masao S. SASAKI, ${ }^{2}$ and Ichiro MATSUdA ${ }^{1}$ \\ 'Department of Pediatrics, Kumamoto University Medical School, \\ Honjo, Kumamoto 860, Japan \\ ${ }^{2}$ Radiation Biology Center, Kyoto University, \\ Yoshidakonoe-cho, Sakyo-ku, Kyoto 606, Japan
}

\begin{abstract}
Summary A 19-year-old girl is described with microcephaly, shori stature, mental retardation, pigmentation of the skin, and recurrent skin abscesses over the whole body. Her elder brother and sister both showed growth and developmental retardation, microcephaly, and anemia. Both died during childhood. Their parents were first cousins. Laboratory studies of the proband revealed hyperchromic erythrocytes with an increased $\mathrm{HbF}$ content, thrombocytopenia, an impaired mitogenic response of the PHA-stimulated lymphocytes, and partial impairment of humoral and cellular immunity. She developed pancytopenia in the terminal stage of the disease. Cytogenetic studies of the bone marrow revealed $46, \mathrm{XX}$, $15 \mathrm{p}+,-18,+$ mar karyotype, increased chromosomal aberrations and sister chromatid exchanges, in cultured lymphocytes and skin fibroblasts. She died at age 20. Thus, the disorder in the patient was deduced as an unclassified chromosomal breakage syndrome with an apparently autosomal recessive inheritance.

Key Words immune deficiency, pancytopenia, preleukemia, autosomal recessive inheritance, chromosome instability syndrome
\end{abstract}

\section{INTRODUCTION}

The Bloom syndrome, Fanconi anemia and Luis-Bar syndrome are all autosomal recessive disorders with an increased tendency towards chromosomal aberrations in cells in vitro (German, 1969). There is a tendency towards malignancy and

Received March 19, 1990; revised version received August 16, 1990; Accepted August 17, 1990. 
immunological disturbances in all three disorders. Clinically and cytogenetically, these syndromes are clearly different from one another, but some unclassifiable cases have been reported in the literature (Marashio et al., 1986; Conley et al., 1986). The present paper deals with a patient with an unclassified chromosomal instability syndrome, with clinical and laboratory features corresponding to some of the Bloom syndrome, Fanconi anemia or Nijmegen syndrome (Weemaes et al., 1981), in addition to intractable skin abscesses, which has not been previously recorded in any of these syndromes.

\section{CASE REPORT}

The proband, a girl, was born as the third child of healthy parents who were first cousins, after a pregnancy of 38 weeks and birth weight of $3,200 \mathrm{~g}$. Her elder brother had died of measles pneumonia at age 8 and elder sister of intracranial bleeding at age 7 . While alive, both showed microcephaly, growth and developmental retardation, and anemia (brother's $\mathrm{RBC}, 660-1,660 \times 10^{3} / \mathrm{mm}^{3}$ ) or pancytopenia (sister's RBC, $1,080 \times 10^{3} / \mathrm{mm}^{3}$; nuclear cell count in bone marrow, $10,375 /$ $\mathrm{mm}^{3}$ ). No other details are known of them. Polio vaccination of the proband at 1 year of age was tolerated without sequelae. She appeared healthy until age 6 years, when she developed pyelonephritis and then measles pneumonia. Her growth delay became apparent at around this age. From age 11 years, she suffered repeatedly from severe skin abscesses. At age 15 years, she was hospitalized for the treatment of skin abscesses, but no improvement was noted. When first examined by us at age 19 , she measured $140.2 \mathrm{~cm}(-3.3$ \# S.D.), weighed $33.9 \mathrm{~kg}(-2.7$ \# S.D.) and head circumference $49.5 \mathrm{~cm}(-3$ \# S.D.). She had neither teleangiectatic erythema nor photosensitivity. Her skin was oily and dirty (Fig. 1). Staphylococcus epidermides skin abscesses were seen all over the body, accompanied by numerous scars and irregularly pigmented areas. Her breast and pubic hair development was at the Tanner stage 2. Skeletal abnormalities were not observed. Her IQ was 46 . A menarche was age 15. Since then, her menses has been irregular and amenorrhea continued for at least last 2 years.

Laboratory examination of the peripheral blood revealed: $\mathrm{RBC}, 3,640 \times 10^{3} /$ $\mathrm{mm}^{3} ; \mathrm{Hb}, 13.2 \mathrm{~g} / \mathrm{dl} ; \mathrm{MCV}, 110.4 \mu \mathrm{m}^{3} ; \mathrm{MCH}, 36.1 \mathrm{pg} ; \mathrm{MCHC}, 32.7 \% ; \mathrm{HbF}, 36.0$ $\%$; WBC, $5,400 / \mathrm{mm}^{3}$ (band form $4 \%$, segmented granulocytes $41 \%$; lymphocytes, $17 \%$; monocytes, $38 \%$; platelets, $27 \times 10^{3} / \mathrm{mm}^{3}$. The nuclear cell count in the bone marrow was $50 \times 10^{3} / \mathrm{mm}^{3}$ and the $\mathrm{M} / \mathrm{E}$ ratio The 2.4 . megakarycytes were small and decreased in number. Megaloblastic changes in the erythroblasts and abnormal cells of monocyte and granulocyte lineage $(18 \%)$ were seen in bone marrow specimens. The colony-formation test was negative.

Normal serum levels included albumin, ferritin, electrolytes, transaminases, zinc, copper, vitamin $\mathrm{B}_{12}$ and folic acid. The serum iron level was slightly reduced $(47 \mu \mathrm{g} / \mathrm{dl})$, whereas serum immunosuppressive acid protein $(810 \mathrm{ng} / \mathrm{ml})$ and lysozyme $(18.5 \mu \mathrm{g} / \mathrm{ml})$ were both elevated. Serum thyroid and growth hormone levels were 


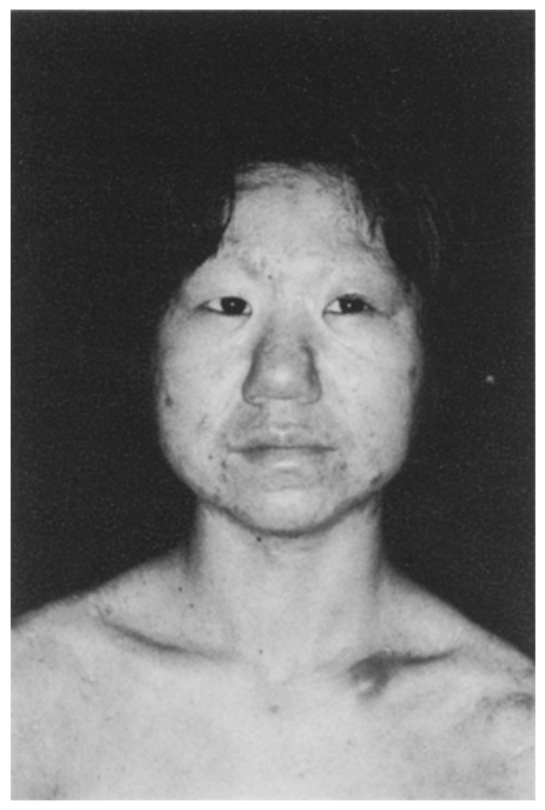

Fig. 1. The patient at age 19 years. Note a round facies with hypertelorism, epicanthal folds, a bulbous nose and thick lips. The skin is covered with many abscesses, numerous scars and pigmented and depigmented areas left over after healing abscesses.

normal without and with stimulation. Urinary excretion of methylmalonic acid, formiminoglutamate and orotic acid was within the normal limits. Serum IgG, $\operatorname{IgA}, \operatorname{IgM}, \operatorname{IgD}$, and $\operatorname{IgE}$ levels estimated on eight separate occassions were $1,141 \pm$ $256.6 \mathrm{mg} / \mathrm{dl}, 304 \pm 60.1 \mathrm{mg} / \mathrm{dl}, 115 \pm 27.0 \mathrm{mg} / \mathrm{dl}, 2.6 \pm 0.4 \mathrm{mg} / \mathrm{dl}$, and $562 \pm 23.8$ $\mathrm{IU} / \mathrm{ml}$, respectively. The ASO, measles and polio antibody titers were $<\times 20$, $<\times 4$, and $<\times 4$, respectively. The total hemolytic complement activity was normal, as were the levels of $\mathrm{C} 3$ and $\mathrm{C} 4$. Intradermal skin tests were positive to PHA and 2,4-dinitro-1-chlorobenzene, but negative to candida antigen, purified protein derivative and streptokinase-streptodornase. Granulocyte function tests were all normal including chemotaxis, phagocytosis, $\mathrm{O}_{2}^{-}$production and adherence. Her lymphocytes demonstrated reduced $\left[{ }^{3} \mathrm{H}\right]$ thymidine uptake on PHA $(4.0 \%)$, Con A (8.6\%), and Pokeweed mitogen (8.6\%) stimulation compared to a control $(100 \%)$. The surface marker subpopulations of lymphocytes were normal. Interleukin (IL)-1 production of her lymphocytes was normal, whereas IL-2 production was reduced to $5.9-20.4 \%$ of the control level.

\section{Cytogenetic studies}

Direct analysis of the patient's bone marrow cells showed a 46,XX,15p+,-18, + mar karyotype in all 30 cells analyzed, while in PHA-stimulated peripheral blood lymphocytes were $46, \mathrm{XX}$. Chromosomal aberrations in cultured lymphocytes 
without and with mitomycin $\mathrm{C}(0.01 \mu \mathrm{g} / \mathrm{ml})$ were $0.11 /$ cell and $0.18 /$ cell (Table 1), respectively, indicating spontaneously increased aberrations but without enhancement with mitomycin $\mathrm{C}$ treatment.

The fluorescence-plus Giemsa method of Perry and Wolff (1974) was used for sister-chromatid differential staining of cells, grown with $40 \mu \mathrm{M} 5$-bromodeoxyuridine. The frequency of sister-chromatid exchanges (SCE) was increased at 64.9/lymphocyte (mother's lymphocytes, 5.6/cell) and 20.0/skin fibroblast (Fig. 2).

\section{Clinical course}

The patient developed 8 months after admission poor appetite and pancytopenia with $>10 \%$ peripheral blood blast cells. Skin absccesses worsened and candidiasis developed in the next 6 months. Her clinical features were not improved by the

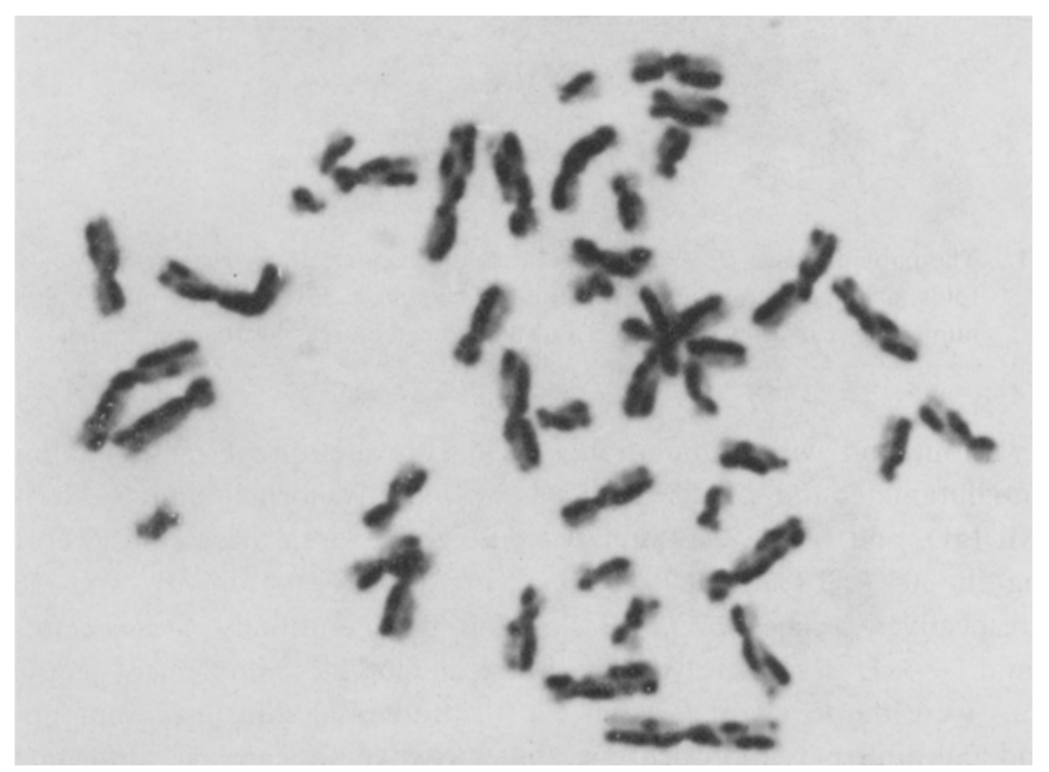

Fig. 2. Increased sister chromatid exchanges in a metaphase from cultured peripheral blood lymphocytes of the patients.

Table 1. Response of peripheral blood lymphocyte chromosome for mitomycin C (MMC) treatment.

\begin{tabular}{lccccccccccc}
\hline & $\begin{array}{c}\text { No. of } \\
\text { cells }\end{array}$ & Dic & Ring & Mo & Frag & ctg & ctb & cte & csg ct aberr. \\
cell
\end{tabular}

Dic, dicentrics; Ring, ring; Mo, abnormal monocentrics; Frag, acentric fragments; ctg, chromatid gap; ctb, chromatid break; cte, chromatid exchange; csg, chromosome gap. 
administration of vitamin $B_{12}$, folic acid, blood transfusion or parental alimentation. She died at age 20 . Autopsy was not granted.

\section{DISCUSSION}

The patient we described showed postnatal growth and developmental retardation, skin abscesses, hyperchromic anemia, partial impairment of the cellular and humoral immunity, increased gaps, breaks and fragments in the chromosomes of cultured deripheral blood lymphocytes, increased sister chromatid exchanges in peripheral blood lymphocytes and skin fibroblasts, an abnormal chromosome 18 in bone marrow cells, terminal pancytopenia and a fatal outcome at age 20 years. Her head was small but proportionate to her stature. She had a senile appearing, round facies with hypertelorism and inner epicanthal folds of the palpebral fissures. Her skin was dark and oily, with numerous abscesses and scars and pigmented and depigmented areas left over after healing skin abscesses. These findings put together, she apparently suffered from a chromosome instability disorder.

Impaired humoral and cellular immunity detected in the patient included: 1) the absence of polio and measles antibodies in the face of normal serum immunoglobulin levels, 2) negative response to intradermal candida antigen, purified protein derivative, and streptokinase-streptodornase, but normal response to PHA and

Table 2. Clinical and laboratory of the patient, compared with those in the well-known chromosome instability disorders.

\begin{tabular}{lcccc}
\hline & $\begin{array}{c}\text { Bloom } \\
\text { syndrome }\end{array}$ & $\begin{array}{c}\text { Fanconi } \\
\text { anemia }\end{array}$ & $\begin{array}{c}\text { Nijmegen } \\
\text { syndrome }\end{array}$ & Patient \\
\hline Intrauterine growth retardation & + & + & + & - \\
Stunted growth & ++ & ++ & + & ++ \\
Microcephaly & + & + & + & + \\
Mental retardation & $-\sim \pm$ & + & + & ++ \\
Telangiectasia & ++ & - & - & - \\
Skin abnormalities & ++ & - & + & - \\
$\quad$ Sun sensitivity & \pm & ++ & + & + \\
$\quad$ Hyperpigmentation & - & - & - & +++ \\
$\quad$ Recurrent abscess & - & ++ & - & - \\
Skeletal deformities & + & + & + & + \\
Immunological disturbances & - & ++ & - & ++ \\
Pancytopenia & + & + & & + \\
Tendency towards malignancy & + & + & + & + \\
\hline Spontaneous chromosome aberrations & + & + & & - \\
Mytomycin C sensitivity & - & - & - & ++ \\
High frequency of & & & & \\
\hline sister-chromatid exchanges & ++ & &
\end{tabular}


2,4-dinitro-1-chlorobenzene, 3) reduced mitogenic responses of peripheral blood lymphocytes to PHA, ConA and pokeweed mitogen, and 4) decreased $1 \mathrm{~L}-2$ production.

There were indications that the patient was preleukemic. They included 1) increased serum levels of lysozyme and immunosuppressive acid protein, 2) megalocytic and hyperchromic erythrocytes with an increased hemoglobin $F$ content, 3) thrombocytopenia, 4) an abnormal bone marrow karyotype, and 5) terminal pancytopenia with peripheral blood blast cells.

Her elder brother and sister both suffered from postnatal growth and developmental retardation, microcephaly and anemia. Both died in their childhood. It seems that they suffered from the same disorder as the proband. The absence of skin abscesses in the siblings would be accounted for by their early death. This, together with the fact the parents were first cousins, indicates that the disorder was inherited in an autosomal recessive fasion.

The disorder in the proband is tabulated in Table 1, in comparison with other well known chromosome instability syndromes: Bloom syndrome (German and Takebe, 1989), Fanconi anemia (Schroeder et al., 1976) and Nijmegen syndrome (Weemaes et al., 1981). It is apparent from the table that the disorder in the proband we described shared many features with, but were different from, each of these disorders.

Of these, Bloom syndrome merits comment in view of the fact that it is the only chromosome instability disorder we are aware of with a high frequency of sister chromatid exchanges, as was the case with the patient we described (Chaganti et al., 1974). The patient, however, lacked telangiectasia, sun sensitivity of the skin, and long facies. Telangiectasia and sun sensitivity are not always apparent in Japanese patients with the Bloom syndrome (German and Takebe, 1989). Recurrent skin abscesses, as observed in the patient, has never been reported with the syndrome. Patients with Bloom syndrome usually show reduced levels of serum IgM and IgA, and an impaired response to pokeweed mitogen, but a normal response to PHA (Hütteroth et al., 1975), whereas the patient we described showed normal serum levels of both $\operatorname{IgM}$ and $\operatorname{IgA}$, and a reduced lymphocyte response to pokeweed mitogen and PHA. The disorder in the patient thus is distinct from the Bloom syndrome. A finding of high sister chromatid exchanges excludes newly described chromosome instablity disorders with microcephaly and immunodeficiency (Conley et al., 1986; Maraschio et al., 1986). Another new syndrome, representing familial microcephaly with normal intelligence, immunodeficiency and lymphoreticular malignancies (Seemanova et al., 1985; Teebi et al., 1987) is not likely in our patient, since the patients with syndrome did not have chromosomal instability. An absence of ataxia in our patients again excludes other disease with chromosomal aberrations (Li et al., 1981; German, 1969; Tsukahara et al., 1986). Thus, it seems that the patient suffered from a hitherto undescribed disorder with chromosome instability, partial impairment of humoral and cellular immunity, and preleukemia. 


\section{REFERENCES}

Chaganti, R.S.K., Schonberg, S. and German, J. 1974. A many fold increase in sister chromatid exchange in Bloom's syndrome lymphocytes. Proc. Natl. Acad. Sci. U.S.A. 71: 4508-4512.

Conley, M.E., Spinner, N.B., Emanuel, B.S., Nowell, P.C. and Nichols, W.W. 1986. A chromosomal breakage syndrome with profound immunodeficiency. Blood 67: 1251-1256.

German, J. 1969. Chromosomal breakage syndrome. Birth Defect 5: 117-131.

German, J. and Takebe, H. 1989. Bloom's syndrome. XIV. The disorder in Japan. Clin. Genet. 35: $93-110$.

Hütteroth, T.H., Litwin, S.D. and German, J. 1975. Abnormal immune responses of Bloom's syndrome lymphocyte in vitro. J. Clin. Invest. 56: 1-7.

Li, F.P., Hecht, F., McGaw, P.V. and Potter, N.U. 1981. Ataxia-pancytopenia: Syndrome of cerebellar ataxia, hypoplastic anemia, monosomy 7 , and acute myelogenous leukemia. Cancer Genet. Cytogenet. 4: 189-196.

Maraschio, P., Peretti, D., Lambiase, S., LoCurto, F., Caufin, D., Gargantini, L., Minoli, L. and Zuffardi, O. 1986. A new chromosomal instability disorder. Clin. Genet. 30: 353-365.

Perry, P. and Wolff, S. 1974. New Giemsa method for the differential staining of sister chromatids. Nature 251: 156-158.

Seemanova, E., Passarge, E., Beneskova, D., Houstek, J., Kasal, P. and Sevcikova, M. 1985. Familial microcephaly with normal intelligence, immunodeficiency, and risk for lymphoreticular malignancies: A new autosomal recessive disorder. Am. J. Med. Genet. 20: 639-648.

Schroder, T.M., Tilgen, D., Kruger, J. and Vogel, F. 1976. Formal genetics of Fanconi's anemia. Hum. Genet. 32: 257-288.

Teebi, A.S., Al-Awadi, S.A. and White, A.G. 1987. Autosomal recessive nonsyndromal microcephaly with normal intelligence. Am. J. Med. Genet. 26: 355-359.

Tsukahara, M., Masuda, M., Obshiro, K., Kobayashi, K., Kajii, T., Ejima, Y. and Sasaki, M.S. 1986. Ataxia teleargiectasia with generalized skin pigmentation and early death. Eur. J. Pediatr. 125: 121-124.

Weemaes, C.M.R., Hustinx, T.W.J., Scheres, J.M.J.C., Van Munster, P.J.J., Bakkeren, J.A.J.M. and Taalman, R.D.F.M. 1981. A new chromosomal instability disorder: The Nijmegen breakage syndrome. Acta Pediatr. Scand. 70: 557-564. 